\title{
Dysgraphic Handwriting Development and Inclusive Education: The Role of Interdisciplinary Counseling
}

\author{
Ida M. Bosga-Stork ${ }^{1,2}$, Jurjen Bosga ${ }^{3,4}$, Ruud G. J. Meulenbroek ${ }^{4,5}$ \\ ${ }^{1}$ Praktijk voor Kinderfysiotherapie Heuvelrug en Vallei, Doorn, The Netherlands \\ ${ }^{2}$ Expertisecentrum Uniek, Willem van Oranjeschool, Woudenberg, The Netherlands \\ ${ }^{3}$ Praktijk Bosga-Stork, Doorn, The Netherlands \\ ${ }^{4}$ Donders Institute for Brain, Cognition and Behaviour-Centre for Cognition, Radboud University Nijmegen, \\ Nijmegen, The Netherlands \\ ${ }^{5}$ Directeur Onderwijsinstituut Psychologie en Kunstmatige Intelligentie Donders Centre for Cognition- \\ Radboud University Nijmegen, Nijmegen, The Netherlands \\ Email: idabosga@gmail.com
}

Received 6 July 2015; accepted 8 August 2015; published 11 August 2015

Copyright (C) 2015 by authors and Scientific Research Publishing Inc.

This work is licensed under the Creative Commons Attribution International License (CC BY). http://creativecommons.org/licenses/by/4.0/

(c) () Open Access

\section{Abstract}

With "inclusive education" in the Dutch school system in mind, a new interdisciplinary counseling was conceptualized. Failing handwriting development in Grade 1 was scrutinized to explore the possibilities of interdisciplinary counseling. The development of two children with dysgraphic handwriting was followed in Grade 1, 2 and 3, and contrasted with the general results of their classmates. Teachers, pediatric physical therapists and psychologist used a combination of handwriting, literacy and kinematic measures for assessment and interdisciplinary counseling for diagnosis and decisions on treatment for the two children with dysgraphic handwriting development. For handwriting speed and quality, standardized test scores were used, for spelling and reading, measures from the school following system were extracted. A motoric loop-writing task was used to explore non-linguistic motor development. For the two dysgraphic boys, a combination of handwriting assessment, kinematic assessment, and reading and writing capacities seems to be a sound foundation for interdisciplinary counseling. Dyslectic development proved to be easier to differentiate than visual motor learning disorders. The handwriting test we used (BHK), can distinguish dysgraphia in general by low scores on quality, whereas the handwriting speed might be informative for developmental dyslexia. Speed and spelling combinations are distinctive for developmental dyslexia, but not so for visuo-spatial learning disorders (VSLD). Spatial accuracy in a non-linguistic task is also distinctive for dyslexia, especially in first and second grade, while VSLD cannot be distinguished by spatial accuracy in a non-linguistic task. Our conclusion is that, if obvious measures for remediation of dysgraphic development are insufficient, psychological assessment is imperative for defining underlying disorders. Tacit knowledge and practical expe- 
rience in teachers as well as theoretical and practical knowledge of the pediatric physical therapist, together with solid diagnosis to define constraints for treatment procedures, are needed to start the process of inclusive education in elementary schools.

\title{
Keywords
}

\author{
Dysgraphia, Development, Inclusive Education, Interdisciplinary Primary School
}

\section{Introduction}

Recently substantial changes were made to the Dutch educational system, with the aim to integrate children with "special educational needs" in the existing school system. Elementary schools now have an obligation to provide educational settings for children, fitting their qualities and abilities summarized in terms of "appropriate education" and "duty of care". This has resulted in an educational model that can be phrased as "usual where possible and special when needed" and "no child left behind", following the general international trend of integration and inclusion for children with special educational needs [1] [2].

Integration nevertheless is not an easy process. In practice, a medical dysfunction paradigm is often used for children with special needs, which presumes the validity of qualitative differences between typically and atypically developing children, but proceeds in treating the dysfunction in order to keep the children in a regular existing education program. Inclusion captures an altogether other concept, which leaves the, often unchangeable, dysfunction in place and focuses on trying to adapt the environment [3]-[5]. Theoretically, inclusion is more in line with dynamic-system or ecological-psychology principles, where behavior is the result of a combination of the child's abilities, the task and the environment [6] [7]. The diversity among children is thus supported and explored in order to define alternative programs for learning.

Currently, the introduction of inclusive education in the Netherlands is still overpowered by the process of procedures and system changes and teachers are reluctant to embrace the consequences of inclusive education, but individual teachers are well aware that their experience and expertise is needed for changes on the work floor [5] [8] [9]. In the wake of the Dutch government policy changes, new partnerships have evolved [10]. Within school settings in nine cities in the Netherlands, we have started interdisciplinary teams ("Expertise Centrum Uniek") of psychologists, pediatric speech therapists and pediatric physical and occupational therapists, family counselors and dietitians, exchanging assessments and experience with teachers. Instead of assessing the children at different locations where several specialists assess and treat children and advising teachers, without knowledge of each others interventions, we now work close to the educational setting in order to develop a process of interdisciplinary counseling, encouraging discussions and cooperation. At the same time we aim at avoiding adverse messages for parents and teachers coming from different specialists. In this paper we report this new way of interdisciplinary counseling in view of the individual assessments and subsequent treatment decisions for two boys experiencing comparable slow and illegible handwriting development in Grade 1 but stemming from different learning disorders.

Handwriting is a complex skill that requires formal instruction in the first three years of primary school. Handwriting is more than a motor act alone, it is fundamentally a core cognitive process for the development of writing skills in general. To develop skilled handwriting, an integration of perceptuo-motor and spelling and reading capacities is necessary [11]-[20]. Reading, spelling and writing by hand are known to be learned in a multimodal fashion. Writing letters by hand results in better recognizing the letters while reading and also results in better spelling when compared to letter typing [21]-[23]. Research is clear on the fact that difficulties in spelling and handwriting affect written expression [24] [25]. Over the years much attention is given to interventions for dysgraphic handwriting development, defining how to instruct letter and word formation [17] [26]-[28]. In school systems, handwriting methods have incorporated this knowledge. Nevertheless, the individual differences in talent, maturity, experience, cognition and rate of development are characteristic for children in the first three years of handwriting development. For example, research shows that the season of birth is related to achievement and diagnosis of specific learning disorders [29] [30]. As regards handwriting development, some children start too young and have a short attention span, sometimes loosing grip on letterform instructions and consequently show slow progress. This can, in some cases, be a hindrance for (written) reading and spelling 
production [22] [23]. Overall, learning to write by hand is an ongoing adaptive process of tuning perceptuomotor and attention abilities to linguistic targets.

Since handwriting development is primarily supported by the school system, communication between teachers and therapists is imperative [31]. To enable teachers and therapists to start a process of interdisciplinary counseling for children with handwriting dysfunction, we developed an experimental assessment procedure to facilitate detection of motor problems due to failing handwriting development in the face of the complexity of literacy skills. The proper assessment of handwriting development seems in need of interdisciplinary teamwork, since about $7 \%$ - $27 \%$ of typically developing children are reported to experience serious problems in mastering the complex skill of handwriting, while not yet being diagnosed for possible learning disorders [32]-[37].

In this study, two boys, who showed a dysgraphic handwriting development in Grade 1, were followed over three years of literacy development. The individual development of the two boys was contrasted with the general development of their schoolmates. Handwriting quality and speed measures, together with kinematic measures, were collected to define the motor capacity, while spelling and reading measures from the school following system represented literacy. After the first interdisciplinary counseling between teacher and pediatric physical therapist, a further assessment of the psychologist was proposed and added to define the constraints resulting learning disorders. The implications for the treatment choices for the individual boys are discussed in the light of interdisciplinary considerations.

\section{Method}

\subsection{Participants}

In first grade, two boys (6.9 and 7.4 years of age, both right handed) in this study showed a disability to produce legible handwriting. At the end of second grade, one boy was diagnosed with dyslexia by the school educationalist, while the psychologist diagnosed the other boy with a visual-spatial learning disorder.

The boys belonged to a group of thirty-two children who attended a primary school in the center of The Netherlands, where an interdisciplinary team was based. They all were followed in 1st, 2nd and 3rd grade and participated in all sessions. The group consisted of fifteen girls and seventeen boys with a mean age of 7.1 (years; month) in Grade 1 (range 6.4 - 7.6). Four girls and two boys were left-handed. All participants had normal hearing and normal or corrected-to-normal vision, were of Caucasian race and had the Dutch language as their first language.

\subsection{Procedures and Materials}

To investigate the interrelationships between developing spelling, reading and handwriting skills the children were assessed in Grade 1, Grade 2 and Grade 3. The first assessment took place in March in primary grade, where printing letters just finished, they starting to learn cursive handwriting. The children were re-assessed in the same month in Grade 2, with a last assessment, also in March in Grade 3, when starting intermediate grade. For the language skills we extracted the mid-grade rating out of the school-based following system for reading and spelling. For handwriting, a copying task was used and scored with a standardized scale reflecting legibility and speed. To capture motor proficiency in the absence of linguistic processing, a loop-writing task was used [38] [39]. For the loop-writing spatial and temporal demands were manipulated by imposing different target amplitudes, and an acoustic pacing signal. The scores of two children identified by the standardized handwriting scale as having a dysgraphia in Grade 1, were contrasted with the group data.

The primary school's institutional review board approved the study and each year the parents of the children gave their informed consent and all children agreed to participate. Each child received a little present after the experiment. Experimental procedures followed the APA guidelines for the ethical treatment of human participants.

\subsubsection{Language Skill Measure: Reading and Spelling}

For each child in each grade, language-performance measures were extracted from the standardized child educational monitoring system (LOVS), which is used by schools to identify students with difficulties and to plan appropriate support. The test scores of the LOVS reflect the impact of the offered education at three different levels: the individual student, group results and school achievement as a total. The tests are developed by the CITO (Central Institute for Test Development), and comply with the criteria for quality of COTAN (Commis- 
sion Test items Netherlands). The spelling test scores from the mid-grade evaluation period were used. For the individual child the LOVS system calculates, among other measures, a "didactical age" expressed as the sum of all educational months, with a total of 10 months for each school year, a "didactical age" equivalent for a specific test score, expressed in educational months, and a learning output percentage (LOP) as a relative norm score. A LOP of $100 \%$ means that a pupil meets the learning demands of his/her grade, a higher percentage reflects that the pupil is a fast learner, a lower percentage reflects he/she is a slow learner. Finally the LOVS has an A to E score in relation to national scoring levels (followed by the LOP in brackets, which differs slightly for grade, adapted by the LOVS to grade and national mean): A: 25\% of highest scores (LOP: > 116\%); B and C: $25 \%$ just above and 25\% just below national level (LOP 84\% - 116\%); D: $15 \%$ below national level and E (LOP: $83 \%-67 \%): 10 \%$ of lowest scores (LOP $<66 \%$ ).

Two language measures were included in the present study. The first, AVI, a test package for reading [40] is taken individually, measuring how fast children read under speed and accuracy constraints that are appropriate for their age, the second, the Spelling Test (Cito, 2006), which gauges spelling in writing words to dictation, is taken in group session in the classroom. Both measures are expressed in terms of learning output percentage.

\subsubsection{Handwriting Product Performance}

The Concise Assessment Scale for Children’s Handwriting (acronym: BHK) [41] was used to assess quality (legibility) and speed of handwriting. For Dutch children the BHK is the most frequently used test. This test is still valid in comparison to the in 2014 published shorter version, which uses only six items for screening purposes [42] [43]. Furthermore the handwriting speed norms are in agreement with the SOS speed norms [43] [44]. The quality score is norm-referenced for children in Grade 2 and 3 and the scoring for speed uses norm-scores for children in Grade $1-6$. The test consists of copying a standard text for 5 minutes, or five lines if the child is a very slow writer. The test was administered in a classroom setting and all children were asked by their teacher to copy a preprinted text on a plain sheet of A4 paper using their usual pencil or pen. Handwriting quality was evaluated by assessing 13 performance characteristics, i.e. 1) writing too large; 2) widening of left-hand margin; 3) bad letter or word alignment; 4) insufficient word spacing; 5) acute turns in connecting joins of the letters; 6) irregularities in joins and/or absence of joins; 7) collisions of letters; 8) inconsistent letter size; 9) incorrect relative height of the various kinds of letters; 10) letter distortion; 11) ambiguous letter forms; 12) correction of letter forms and 13) unsteady writing trace. The first two items are scored on the basis of the entire written work. Both items are measured on an ordinal scale with six categories resulting in a score form 0 to 5 . For the first item (size of writing) the actual size of the letter is measured using a transparent sheet provided by the test. This size is converted to a score from 0 (which stands for appropriate for age) to 5 which is much too large for age. For item 2, the transparent sheet is used as well, measuring the slope of the left hand margin from no deviation from the straight line (0) to strong deviation from the straight line (5). For the remaining 11 items, the first five sentences are scored as to whether or not a particular feature is present in that sentence. A score of 1 is given when present, with five sentences to score, the maximum score for each feature amounts to five. The child's total score on all 13 items is categorized according to whether their handwriting is in the typical range, or "not-dysgraphic" (a score of 0 - 21), ambiguous (22 - 28) or whether they are considered to have a handwriting difficulty, referred to as "dysgraphia" (29 or higher). The quality of the handwriting was assessed independently by two experienced pediatric physical therapists. When no agreement was reached, a third experienced pediatric physical therapist was consulted whose opinion was decisive. Since there are no norm-references for children in Grade 1, two experienced teachers were asked to apply one of the three categories, by analyzing the quality of the handwriting using their knowledge of developing handwriting. On two children there was no agreement, a third teachers' opinion was decisive. Handwriting speed was measured by counting the number of letters produced in exactly five minutes and translated in deciles scores related to the child's Grade. The deciles 1 and 2 reflect a slow writer, while deciles 9 and 10 reflect a fast writer. Those in between were categorized as "typical writers". Interrater reliability of the BHK varied between $r=0.71$ and $r=0.89$; intrarater reliability was $r=0.87$ to $r=0.94$ for Grade 2 and $r=0.79$ to $r=0.88$ for Grade 3, while the test-retest reliability has been reported as $0.51-0.55[41]$.

\subsubsection{Kinematic Performance}

Handwriting performance was further evaluated using a non-linguistic loop-writing task performed with an electronic ink pen (Intuos3) on a digitizer (WACOM A4 Oversize tablet). Paced by means of an acoustic signal, the children were asked to draw loops of different heights $(3,6,9$ and $12 \mathrm{~mm})$ and frequencies $(1,2 \mathrm{and} 3 \mathrm{~Hz})$. 
The pacing signals changed sinusoidal in intensity across a clearly audible range (approximately 60 - $70 \mathrm{~dB}$; tone pitch $330 \mathrm{~Hz}$ ). Each of 12 preprinted trial sheets consisted of six repetitions (block) of the twelve amplitude-frequency combinations and was presented at random. Amplitude-frequency combinations within the six trials of a block remained constant. Each child was asked to perform 72 trials of 18 loops each, leading to a theoretical total of 1296 loops per experiment at age 7, 8 and 9 (i.e. a maximum of 3888 loops per child). On-line recordings of $\mathrm{X}, \mathrm{Y}$ and $\mathrm{Z}$ (axial pen force) were sampled at $200 \mathrm{~Hz}$. Before the experiment started, the task was explained and the children allowed performing the task a few times to get comfortable with the experimental procedures and task requirements. For this purpose, each of the three frequencies was performed twice, using the 9 and $12 \mathrm{~mm}$ loop patterns, thus yielding 12 practice trials, in Grade one. In grades two and three each of the three frequencies was practiced twice, using only the 9-mm loop pattern (6 practice trials). The children were tested individually in a quiet room in the school, seated on an adjustable chair, with their feet supported and in a writing position adapted to the digitizer tablet.

\subsection{Statistical Analysis}

A reliability analysis was carried out for the thirteen items of the BHK, in order to be certain that the analysis of the handwriting product was sufficiently homogeneous for this specific group and could be used as reference for two children with learning disabilities. The reliability of the handwriting scale (BHK) proved sufficient. In Grade 2 Cronbach's alpha amounted to 0.70, in Grade 3 Cronbach's alpha was 0.82 . Correlations between all pairs of test scores at each grade were explored to isolate interdependencies. Those literacy skills that that were significantly correlated (either positively or negatively) were further analyzed by means of linear regression analyses in which the children's individual scores were the dependent measures. To highlight the specific development of the two boys, the speed and quality measures of the handwriting task, the reading and spelling measures for the literacy and the absolute error of the amplitudes (AEAmp) of the loop-writing task were used, based on the correlations we isolated and which might fit with our experimental assessment procedure. Furthermore we included the handwriting quality measure, since handwriting quality and speed are considered to be two independent measures for handwriting proficiency.

For the loop-writing task, the 18 loops of 72 trials per age were used to define the mean of the differences between the instructed and realized amplitudes and frequencies. For the exact method for analysis we refer to reference 39. The critical alpha was set at $\mathrm{p}=0.05$. SPSS 19 was used for the statistical analyses.

\section{Results}

\subsection{General Group Performance}

The means, standard deviations (SD) and minimum and maximum scores for the handwriting-, language- and loop-writing performance for the children in each grade are shown in Table 1. The general performance shows an increase in proficiency in handwriting speed and quality. For reading the group shows an increase of the competence in reaching the requirements of their grade, while this competence for spelling does show an increase from grade 1 to 2, but in grade 3 the competence for spelling seems to stabilize, nevertheless the groups mean is still well above the requirements for grade. For the kinematic measures, the errors in amplitude and frequency for the loop-writing task decrease.

\subsection{Inter Correlations between All Measures}

The Pearson product-moment correlations between handwriting production, language and loop-writing performance for each grade separately are given in Table 2. Handwriting speed shows a significant positive correlation with reading and spelling in Grade $1(r=0.51$ and 0.39 respectively) and Grade $3(r=0.39$ and 0.37 respectively) but only with spelling in Grade $2(\mathrm{r}=0.55)$. Reading and Spelling were statistically significant positive correlated in Grades 1, 2 and 3 ( $r=0.40,0.72$ and 0.52 respectively). The absolute error of amplitude (AEAmp) is statistically significant negatively correlated with Reading and Spelling, but only in Grade $1(r=-0.45$ and -0.46 respectively). No correlations were found in the frequency domain.

\subsection{Handwriting Speed and Quality}

Next we examined handwriting production speed as a function of the handwriting quality score (Figure 1). In 
Table 1. Descriptive statistics for handwriting speed and quality, language performance (reading and spelling LOP) and loop-writing performance for amplitude (AEAmp) and frequency (AEFreq) errors, differentiated for each measure for Grades 1, 2 and 3.

\begin{tabular}{ccccccc}
\hline & \multicolumn{2}{c}{ Grade 1} & \multicolumn{2}{c}{ Grade 2} & \multicolumn{2}{c}{ Grade 3} \\
\hline & Mean [SD] & Min-Max & Mean [SD] & Min Max & Mean [SD] & Min - Max \\
\hline Handwriting speed & $57[23]$ & $15-100$ & $125[36]$ & $56-203$ & $200[50]$ & $133-357$ \\
Handwriting quality & - & - & $18[7]$ & $5-37$ & $15[9]$ & $2-43$ \\
Reading (LOP) & $112[77]$ & $14-214$ & $133[67]$ & $29-285$ & $136[46]$ & $23-250$ \\
Spelling (LOP) & $95[57]$ & $57-243$ & $124[55]$ & $33-227$ & $115[36]$ & $27-177$ \\
AEAmp (mm) & $1.52[0.52]$ & $0.67-2.64$ & $1.29[0.56]$ & $0.52-2.61$ & $1.24[0.62]$ & $0.44-3.28$ \\
AEFreq (Hz) & $0.33[0.17]$ & $0.09-0.68$ & $0.24[0.17]$ & $0.09-0.65$ & $0.21[0.13]$ & $0.05-0.53$ \\
\hline
\end{tabular}

Table 2. Summary of correlations for scores on handwriting speed and quality, reading learning percentage for spelling and reading and amplitude and frequency errors for the loop-writing for Grade 1, Grade 2 and 3 separately.

\begin{tabular}{|c|c|c|c|c|c|}
\hline Measure & Handwriting quality & Reading (LOP) & Spelling (LOP) & AEAmp (mm) & AEFreq (Hz) \\
\hline \multicolumn{6}{|l|}{ Grade 1} \\
\hline Handwriting speed & - & $0.51^{* *}$ & $0.40^{*}$ & -0.30 & -0.21 \\
\hline Handwriting quality & & - & - & - & - \\
\hline Reading (LOP) & & & $0.41^{*}$ & $-0.45^{* *}$ & -0.20 \\
\hline Spelling (LOP) & & & & $-0.47^{* *}$ & -0.06 \\
\hline AEAmp (mm) & & & & & -0.23 \\
\hline \multicolumn{6}{|l|}{ Grade 2} \\
\hline Handwriting speed & -0.14 & 0.24 & $0.56^{* *}$ & -0.08 & 0.01 \\
\hline Handwriting quality & & -0.17 & -0.13 & 0.06 & -0.03 \\
\hline Reading (LOP) & & & $0.72^{* *}$ & -0.07 & -0.12 \\
\hline Spelling (LOP) & & & & -0.01 & -0.30 \\
\hline AEAmp (mm) & & & & & -0.33 \\
\hline \multicolumn{6}{|l|}{ Grade 3} \\
\hline Handwriting speed & 0.10 & $0.39^{*}$ & $0.37^{*}$ & 0.08 & -0.28 \\
\hline Handwriting quality & & -0.04 & -0.23 & 0.16 & -0.09 \\
\hline Reading (LOP) & & & $0.52^{* *}$ & -0.10 & -0.21 \\
\hline Spelling (LOP) & & & & -0.11 & -0.06 \\
\hline AEAmp (mm) & & & & & -0.09 \\
\hline
\end{tabular}

${ }^{*}$ Correlation is significant at the 0.05 level (2-tailed). ${ }^{* *}$ Correlation is significant at the 0.01 level (2-tailed).

Grade 1, the general performance of children just started practicing cursive handwriting shows a wide spread for the speed and quality scores, which over the grades clusters toward the norm for age (Figure 1(A) and Figure 1(B)). In Grade 3, nearly all children could write sufficiently fast and neatly (Figure 1(C)).

The boy diagnosed with dyslexia (square) started handwriting production in slow speed in Grade 1 (18 letter/min) and remained slow in handwriting speed over the three years of development (88 letters/min in Grade 2 and 155 letters/min in Grade 3), while handwriting quality was defined as dysgraphic (BHK $\geq 29$ ) in Grade 2 score 37; Grade 3 score 36. The child identified as having a visual-spatial learning disorder (circle) produced 

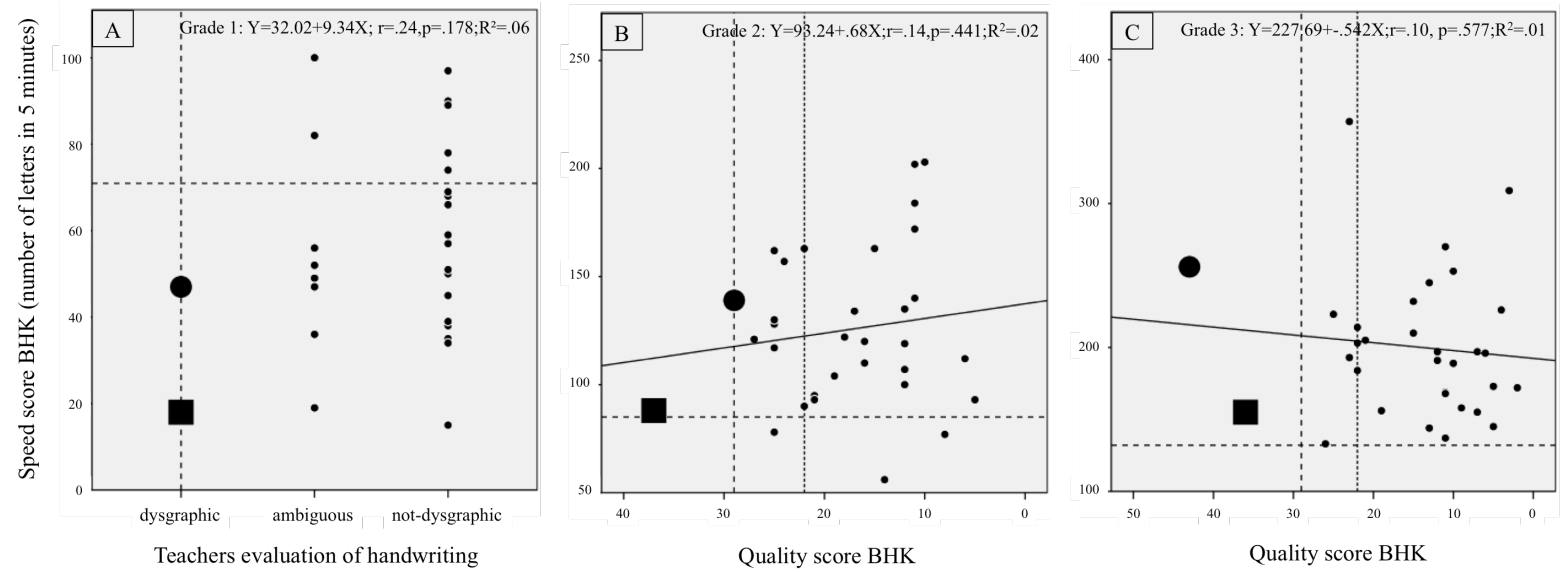

Figure 1. Handwriting speed as a function of handwriting quality as measured by the BHK for Grade (A), Grade 2 (B), and Grade 3 (C). (A) reflects the teacher's evaluation of children who just started to practice cursive handwriting in Grade 1 . Note : The vertical dotted reference line in (A) marks the children showing dysgraphia, the horizontal dotted reference lines mark the $2^{\text {nd }}$ decile for handwriting speed: BHK. The vertical dotted reference lines in (B) and (C) reflect the dysgraphic score $(\geq 29$, wider dots), and ambiguous score $(\leq 22$, small dots). For all figures: Children are plotted as points around the regression lines. In all figures, the black square marks the child with dysgraphia, the black circle the child with visual-spatial learning disorder.

systematically dysgraphic handwriting in Grade 2 and 3 (score 29 and 57 respectively), but could speed up sufficiently: Grade 1: 47 letters/min, Grade 2: 139 letters/min and Grade 3; 256 letters/min. (Figures 1(A)-(C)).

\subsection{Handwriting Speed and Spelling}

The interrelationship between transcription speed and spelling performance was also examined (Figure 2). As a group the children's spelling skill developed from wide spread performance differences (Figure 2(A) and Figure 2(B)) to a more clustered performance around the mean (Figure 2(C)), while transcription speed production increased steadily over the three years (Figures 1(A)-(C)).

The developmental pattern of the two children with dysgraphia in relation to speed and spelling performance was vastly different. The boy with dyslexia developed a serious spelling delay (LOP 57\%, 33\%, 27\%, systematically in the lowest spelling category: E, meaning that he could not reach the requirements for Grade) in combination with slow writing speed $\left(2^{\text {nd }}\right.$ deciles), which remained more or less stable over three years of development (Figures 2(A)-(C)). The child with visual-spatial learning disorders showed spelling skills above the mean for age (LOP 160\%, 140\%, 136\%, in B and A, A, category), in combination with a slow start in the development of handwriting speed production, followed by a high speed, but illegible handwriting production at age 8 and 9 $\left(10^{\text {th }}\right.$ deciles; see Figures 2(A)-(C)).

\subsection{Amplitude Errors and Spelling}

Next we looked at the absolute errors in the amplitude domain (AEamp) of the loop-writing task as a function of language spelling level (Figure 3). At a general level a developmental trend was seen from a widely dispersed error production for children with a lower learning output for spelling towards a clustering around the mean for spelling with less amplitude errors (Figures 3(A)-(C)).

The children with dysgraphia were as widely apart as seen in spelling and speed combinations. In grade 1 and 2 the boy with dyslexia showed errors of about $2 \mathrm{~mm}$ in the amplitude domain in combination with low levels of spelling, in Grade 3 the errors became smaller. The boy with visual-spatial learning disorder produced errors of less than $1.5 \mathrm{~mm}$ in combination with high levels of spelling development (see Figure 3(A) and Figure 3(B)), which remained around the same error level over the three years (see Figures 3(A)-(C)).

\subsection{Reading and Spelling}

Finally, the known interrelation between reading and spelling development was verified for this group (Figure 4). At a general level a clear developmental trend was seen. While still showing diversity in performance in the 

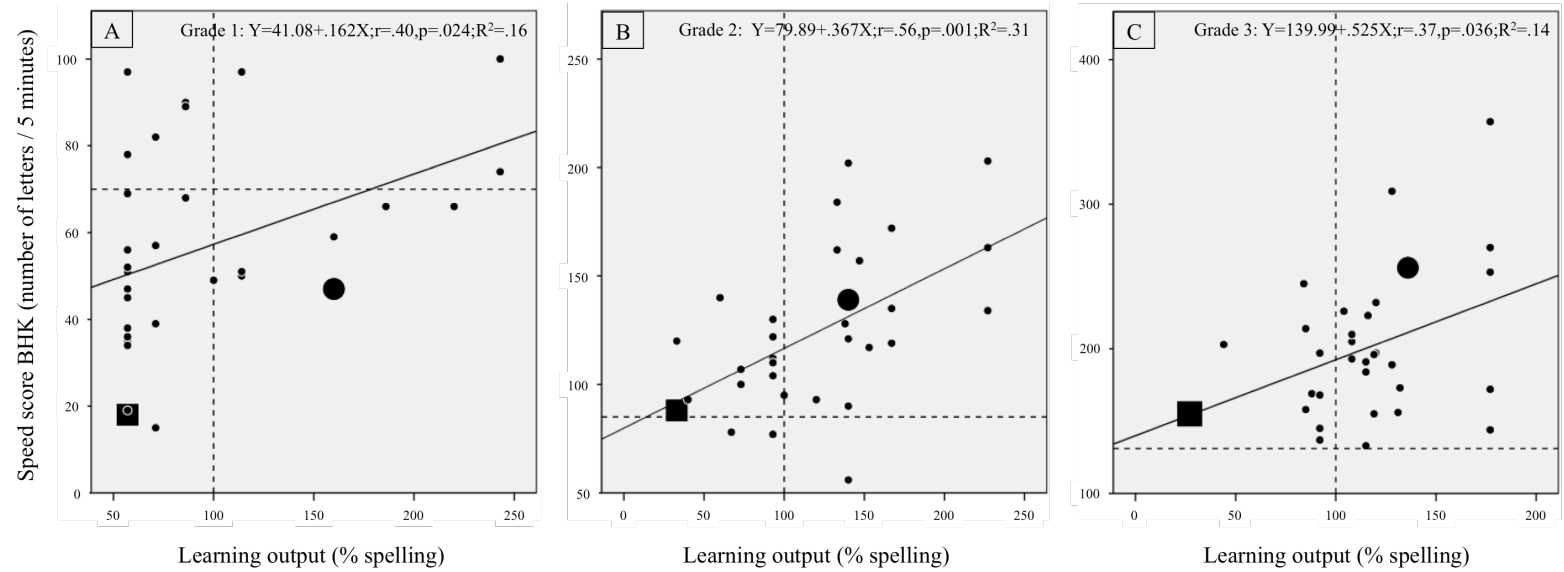

Figure 2. Handwriting speed as a function of the learning output percentage spelling for Grade 1 (A), Grade 2 (B) and Grade (C). Note: The vertical dotted reference lines mark the $100 \%$ learning output for spelling. The horizontal dotted reference lines mark the $2^{\text {nd }}$ decile (BHK) for handwriting speed.

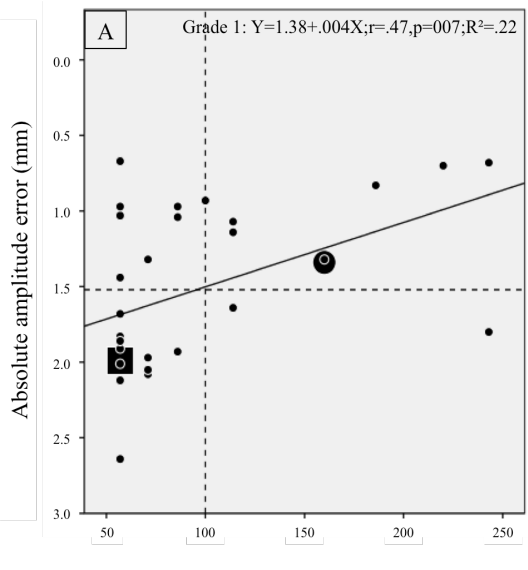

Learning output ( $\%$ spelling)

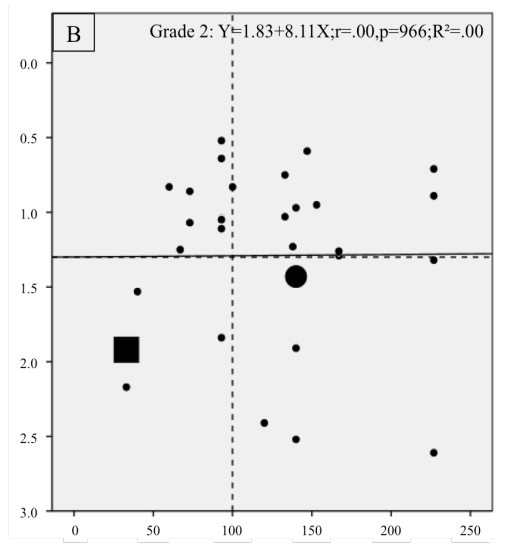

Learning output ( $\%$ spelling)

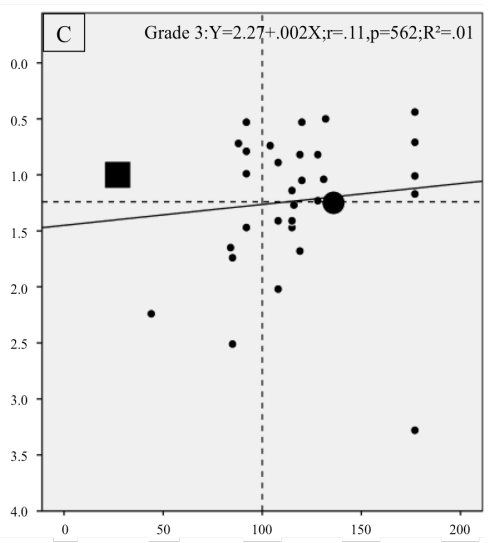

Learning output ( $\%$ spelling)

Figure 3. Absolute error of amplitude (AEAmp) in $\mathrm{mm}$ as a function of the spelling learning output percentage for Grade 1 (A), Grade 2 (B) and Grade 3 (C).

different learning domains, most children showed improving learning outputs with age for reading as well as spelling (Figures 4(A)-(C)).

The two children with dysgraphia performed unquestionably differently from each other. The boy with dyslexia showed a stable learning disorder with a low learning output and no progress in reading or spelling skills over the three years of development: reading LOP $14 \%, 54 \%$ and $23 \%$, a performance that was systematically at the level of Grade 1, without increase in performance. The boy with visual spatial learning disorders showed a stable high learning output for reading $214 \%, 139 \%$ and $180 \%$, meaning he could read well beyond his age: in Grade 1 he reached end Grade 2, in Grade 2, he reached mid Grade 3, while in Grade 3 he reached end level elementary school, thus showing no indication of developmental learning disorders in reading or spelling (see Figures 4(A)-(C)).

\section{Discussion}

In the wake of changes in the Dutch educational system concerning children with special educational needs, a new interdisciplinary team was composed with the intention to effectuate interdisciplinary counseling in school settings, respecting the diversity among children, while focusing on adapting the environment to the special needs and capacities of individual child, also known as Individualized Educational Program (IEP).

The goal of this study was to explore the practical use of a combination of performance measures of literacy 

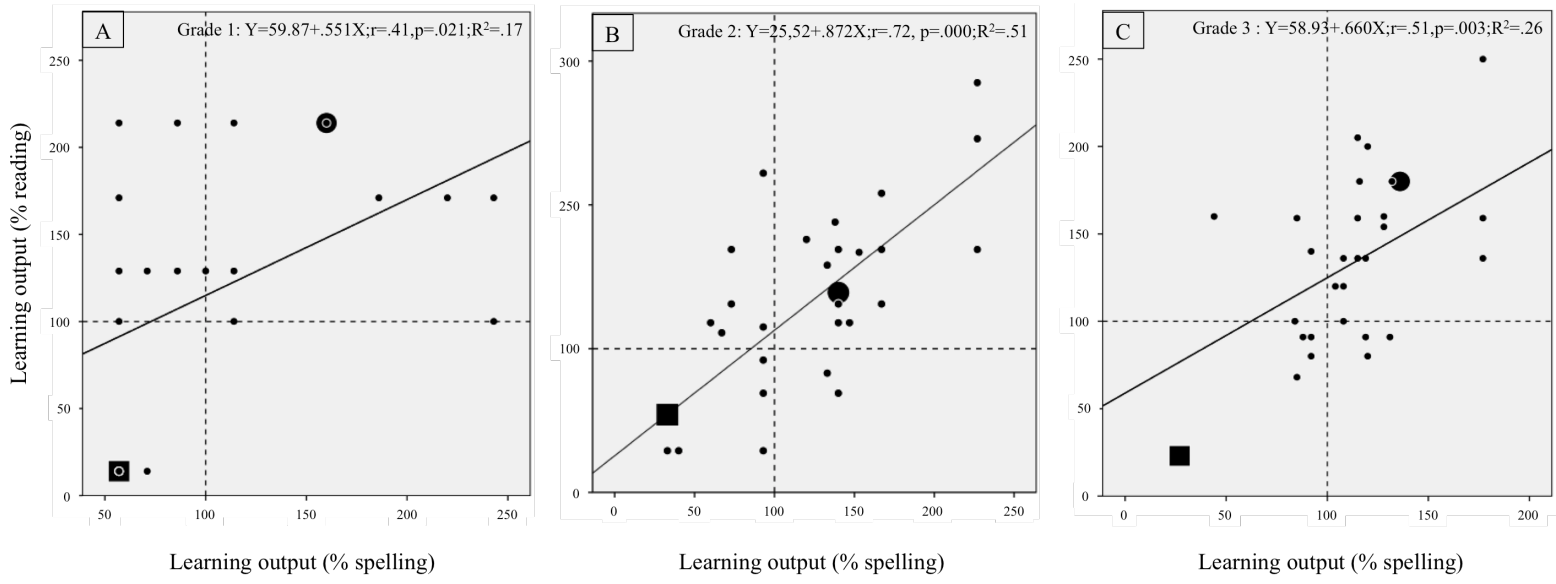

Figure 4. Learning output percentage for reading as a function of the learning output percentage for spelling for Grade 1 (A), Grade 2 (B) and Grade 3 (C).

and motor skills, to decide whether we would be able to isolate children with a learning disorder, expressed in dysgraphia, from their typically developing classmates, who were used as references in this study. As screening method we used a standard Dutch handwriting test for quality and speed (BHK) to define and follow handwriting development and one of the kinematic measures of loop writing (absolute error of amplitude), to define non-linguistic fine motor movements. Since reading and spelling capacities are known to relate to handwriting development, we included standardized learning-output percentages for reading and spelling, extracted from the schools' educational monitoring system. These percentages reflected whether the child was to be considered a slow, typical (normal spread around the mean) or fast learner. Finally, the psychologist set the diagnoses and defined the constraint for the specific learning disorders.

\subsection{The Process of Interdisciplinary Counseling}

Step 1. At the start of handwriting development at the age of 7, halfway through Grade 1, when just starting to write cursive, two boys in this cohort were judged to develop dysgraphic handwriting by their teachers. Following a the first assessments in march by the teacher and physical therapist, both children started an intervention using explicit instruction in motor and orthographic components using visual cues and verbal mediation [26] aimed at legible handwriting in combination with extra tutoring in spelling and reading for the dysgraphic boy with E levels for reading and spelling. Over the first half of Grade 2, neither boy showed progress in legibility and after counseling the decision was made to initiate psychological assessment for both children.

Step 2. The psychologist diagnosed the boy with E-levels for reading and spelling with dyslexia (DSM-5 Specific Learning Disabilities, SLD). Dyslexia is a specific disorder in reading and spelling and is treated by a specialized psychologist, the psychologist also instructs the parents and teacher. The child with dyslexia thus enrolled in the standard (Dutch) dyslexia program in combination with a yearly short-time repetition of handwriting instructions, to focus on form conservation and enough speed. Acceptance of slow handwriting is essential, since these children can write legible but are slow learners, while spelling and reading constraints affect handwriting speed [45]. Handwriting tasks were adapted to the constraints of dyslexia, i.e. tasks were shortened is necessary and slower handwriting speed was incorporated in the classroom assignments.

The boy with A-levels for reading and spelling could write legible directly after treatment in Grade 1, but his handwriting deteriorated over the next months and resulted in a fast production of near doodles. The consulted psychologist diagnosis was a visual-spatial learning disorder (VSLD), resembling what is sometimes called Nonverbal Learning Disability (NLD). After interdisciplinary considerations and parent and child consultation, handwriting was thought not to contribute to his learning capacities and he was taught typing in Grade 3, in combination with instructions of planning skills. At home as well as in school this boy was unable to organize his environment and needed well-defined and strict instructions and work plans [46] [47].

Although both boys were dysgraphic in handwriting performance, they were treated differently, based on the different assessment outcomes for the motoric and language capacities and different constraints arising from di- 
agnoses.

\subsection{Outcome of Experimental Procedure}

Measure 1 (Figure 1): Handwriting speed production in relation to quality.

Both boys showed dysgraphic handwriting over the three years, but only the boy with the dyslectic learning disorder could be singled out on speed. He remained slow in developing handwriting speed and only after three years reached an acceptable speed for his age and disorder. He remained dysgraphic on handwriting tests, although his handwriting became legible. This is in accordance with [34], who found a weak positive but nonlinear correlation between handwriting quality and speed, describing them as approximately independent measures of handwriting proficiency. Furthermore, [48] suggests that greater transcription speed increases automaticity of word production so that a writer's working memory can be freed up for cognitive processes, which is one of the difficulties for dyslectic children. In could be concluded that, speed as well as legibility seem an essential part of diagnostic procedures when looking into dysgraphic development in the first three years of handwriting development.

Measure 2 (Figure 2): Speed production in relation to spelling capacity

Only the boy with dyslexia could be identified as different from the group mean. For the child with VSLD, this test only tells us that spelling development is typical in the face of his peers, while handwriting speed production increases as handwriting quality declines. Here one could speculate that motor capacities might not be the core of this visual-spatial learning disorder. The differences between these boys indicate that this measure might be useful in the diagnostic process and during interdisciplinary counseling.

Measure 3 (Figure 3): Spatial accuracy in loop writing in relation to spelling

In the domain of spatial accuracy, the boy with dyslexia showed a greater amplitude error than the child with VSLD, but his spatial accuracy increased and in Grade 3 equaled his classmates. This task is thought to express motor capacity without language interference and is a measure for the extent of motor deficiency in handwriting skill. It could be speculated that the boy with VSLD showed no primary motor output disorder, but a more cognitive processing disorder, which became apparent in the psychological assessment, were all tests concerning visual perception caused problems. The boy with dyslexia at the other hand, although afflicted with a primary language disorder was unable to develop motor efficiency (slow handwriting). The learning capacity for spelling of the boy with dyslexia remained in the lowest $25 \%$ of his grade, accuracy in motor performance developed slowly, which might indicate a language related disorder and a trainable letter formation. Here again the child with dyslexia could be singled out, which was impossible for the boy with VSLD. For this child defining the cognitive capacity through psychological assessment was essential, followed by interdisciplinary counseling to decide on learning strategies for this child.

Measure 4 (Figure 4): Reading and spelling relations

Reading and spelling capacity for the boy with dyslexia stood out against the capacity of his classmates, while the boy with VSLD showed a capacity well within the mean of his classmates. Again for dyslexia this relation is informative, for VSLD more information is needed, especially diagnostic procedures and information on executive functions.

\section{Limitation of the Study}

The relatively small number of children within a specific context (a school-based learning context in the Netherlands) is a limitation for generalization. Interpretation of the data should therefore be done with caution. Moreover, the combination of assessment tests is an aspect for careful interpretation.

\section{Suggestions for Further Research}

For treatment decisions, general performances of a group of children are less informative than the actual performance of the children themselves. For research, the adoption of a wider set of tests for defining dysgraphia is advisable since language and motor skills are closely connected and care should be taken not to simplify complex skills. Furthermore, interdisciplinary counseling as part of inclusive education should be included in research on remedial procedures. Including a device for kinematic analysis of children's handwriting movements in a school setting may be possible in the near future, since data analysis becomes more sophisticated and easy 
to achieve.

\section{Conclusions}

In conclusion, failing handwriting development in Grade 1 was used to explore the possibilities of counseling in an interdisciplinary team. In this case, a combination of handwriting assessment, kinematic assessment, and reading and writing capacities seems to be a sound foundation for interdisciplinary counseling. The handwriting test we used (BHK), can distinguish dysgraphia in general by low scores on quality, whereas the handwriting speed might be informative for developmental dyslexia. Speed and spelling combinations are distinctive for developmental dyslexia, but not so for VSLD. Spatial accuracy in a non-linguistic task is also distinctive for dyslexia, especially in first and second grade, while VSLD cannot be distinguished by spatial accuracy in a nonlinguistic task.

When obvious measures for remediation of dysgraphic development prove to be insufficient, psychological assessment is imperative for defining underlying disorders. Tacit knowledge and practical experience in teachers as well as theoretical and practical knowledge of the pediatric physical therapist, together with solid diagnosis to define constraints for treatment procedures, are needed to start the process of inclusive education in elementary schools.

\section{References}

[1] Ainscow, M. (2005) Developing Inclusive Education Systems: What Are the Levers for Change? Journal of Educational Change, 6, 109-124. http://dx.doi.org/10.1007/s10833-005-1298-4

[2] Ainscow, M., Howes, A., Farrell, P. and Frankham, J. (2003) Making Sense of the Development of Inclusive Practices. European Journal of Special Needs Education, 18, 227-242. http://dx.doi.org/10.1080/0885625032000079005

[3] Barton, L. (2003) Inclusive Education and Teachers Education. Institute of Education, University of London, London.

[4] Terzi, L. (2005) Beyond the Dilemma of Difference: The Capability Approach to Disability and Special Educational needs. Journal of Philosophy of Education, 39, 443-459. http://dx.doi.org/10.1111/j.1467-9752.2005.00447.x

[5] Schuman, H. (2007) Passend onderwijs: Pas op de plaats of stap vooruit. Tijdschrift voor Orthopedagogiek, 46, 266287.

[6] Newell, K.M. (1986) Constraints in the Development of Coordination. In: Wade, M.G. and Whiting, H.T.A., Eds., Motor Development in Children: Aspects of Coordination and Control. Martinus Nijhoff Publishers, Dordrecht. http://dx.doi.org/10.1007/978-94-009-4460-2_19

[7] Sugden, D.A. and Henderson, S.E. (2007) Ecological Intervention. Pearson Assessment, London.

[8] Pijl, S.J. (2010) Preparing Teachers for Inclusive Education: Some Reflections from the Netherlands. Journal of Research in Special Educational Needs, 10, 197-201. http://dx.doi.org/10.1111/j.1471-3802.2010.01165.X

[9] De Boer, A., Pijl, S.J. and Minnaert, A. (2011) Regular Primary Schoolteachers' Attitudes towards Inclusive Education: A Review of the Literature. International Journal of Inclusive Education, 15, 331-353. http://dx.doi.org/10.1080/13603110903030089

[10] Thijs, A., Van Leeuwen, B. and Zandbergen, M. (2009) Inclusive Education in the Netherlands. Ministry of Education, Culture and Science, Enschede.

[11] Abbott, R.D., Berninger, V. and Fayol, M. (2010) Longitudinal Relationships of Levels of Language in Writing and between Writing and Reading in Grades 1 to 7. Journal of Educational Psychology, 102, 281-298. http://dx.doi.org/10.1037/a0019318

[12] Berninger, V.W. (2000) Development of Language by Hand and Its Connections with Language by Ear, Mouth, and Eye. Topics in Language Disorders, 20, 65-84. http://dx.doi.org/10.1097/00011363-200020040-00007

[13] Berninger, V.W., Abbott, R.D., Jones, J., Wolf, B.J., Anderson-Youngstrom, M., Shimade S. and Apel, K. (2006) Early Development of Language by Hand: Composing, Reading, Listening, and Speaking Connections; Three LetterWriting Modes; and Fast Mapping in Spelling. Developmental Neuropsychology, 29, 61-92. http://dx.doi.org/10.1207/s15326942dn2901_5

[14] Berninger, V., Fuller, F. and Whitaker, D. (1996) A Process Model of Writing Development across the Life Span. Educational Psychology Review, 8, 193-218. http://dx.doi.org/10.1007/BF01464073

[15] Flower, L. and Hayes, J.R. (1981) A Cognitive Process Theory of Writing. College Composition and Communication, 32, 365-387. http://dx.doi.org/10.2307/356600

[16] James, K.H. and Gauthier, I. (2006) Letter Processing Automatically Recruits a Sensory-Motor Brain Network. Neu- 
ropsychologia, 44, 2937-2949. http://dx.doi.org/10.1016/j.neuropsychologia.2006.06.026

[17] Jones, D. and Christensen, C.A. (1999) The Relationship between Automaticity in Handwriting and Students' Ability to Generate Written Text. Journal of Educational Psychology, 91, 44-49. http://dx.doi.org/10.1037/0022-0663.91.1.44

[18] Rijlaarsdam, G. and Van den Bergh, H. (2006) Writing Process Theory: A Functional Dynamic Approach. In: MacArthur, C.A., Graham, S. and Fitzgerald, J., Eds., Writing Research, Guildford Press, New York, 41-53.

[19] Van Galen, G.P. (1991) Handwriting: Issues for a Psychomotor Theory. Human Movement Science, 10, 165-191. http://dx.doi.org/10.1016/0167-9457(91)90003-G

[20] Childress, A. (2011) Understanding Writing Problems in Young Children: Contributions of Cognitive Skills to the Development of Written Expression. Ph.D. Thesis, University of North Carolina, Chapel Hill.

[21] Cunningham, A.E. (1990) Explicit versus Implicit Instruction in Phonemic Awareness. Journal of Experimental Child Psychology, 50,429-444. http://dx.doi.org/10.1016/0022-0965(90)90079-N

[22] Longcamp, M., Anton, J.L., Roth, M. and Velay, J.L. (2003) Visual Presentation of Single Letters Activates a Premotor Area Involved in Writing. Neuroimage, 19, 1492-1500. http://dx.doi.org/10.1016/S1053-8119(03)00088-0

[23] Longcamp, M., Boucard, C., Gilhodes, J.C., Anton, J.L., Roth, M., Nazarian, B. and Velay, J.L. (2008) Learning through Hand- or Typewriting Influences Visual Recognition of New Graphic Shapes: Behavioral and Functional Imaging Evidence. Journal of Cognitive Neuroscience, 20, 802-815. http://dx.doi.org/10.1162/jocn.2008.20504

[24] Berninger, V.W., Rutberg, J.E., Abbott, R.D., Garcia, N., Anderson-Youngstrom, M., Brooks, A. and Fulton, C. (2006) Tier 1 and Tier 2 Early Intervention for Handwriting and Composing. Journal of School Psychology, 44, 3-30. http://dx.doi.org/10.1016/j.jsp.2005.12.003

[25] Graham, S. and Harris, K.R. (2006) Preventing Writing Difficulties: Providing Additional Handwriting and Spelling Instruction to At-Risk Children in First Grade. Teaching Exceptional Children, 38, 64-66.

[26] Berninger, V.W., Vaughan, K.B., Abbott, R.D., Abbott, S.P., Rogan, L.W., Brooks, A., Reed, E. and Graham, S. (1997) Treatment of Handwriting Problems in Beginning Writers: Transfer from Handwriting to Composition. Journal of Educational Psychology, 89, 652-666. http://dx.doi.org/10.1037/0022-0663.89.4.652

[27] Graham, S., Weintraub, N., Berninger, V. and Schafer, W. (1998) Development of Handwriting Speed and Legibility in Grades 1-9. Journal of Educational Research, 92, 42-52. http://dx.doi.org/10.1080/00220679809597574

[28] Chartrel, E. and Vinter, A. (2008) The Impact of Spatio-Temporal Constraints on Cursive Letter Handwriting in Children. Learning and Instruction, 18, 537-547. http://dx.doi.org/10.1016/j.learninstruc.2007.11.003

[29] Martin, R.P., Foels, P., Clanton, G. and Moon, K. (2004) Season of Birth Is Related to Child Retention Rates, Achievement, and Rate of Diagnosis of Specific LD. Journal of Learning Disabilities, 37, 307-317. http://dx.doi.org/10.1177/00222194040370040301

[30] Oshima, T.C. and Domaleski, C.S. (2006) Academic Performance Gap between Summer-Birthday and Fall-Birthday Children in Grades K-8. The Journal of Educational Research, 99, 212-217. http://dx.doi.org/10.3200/JOER.99.4.212-217

[31] Effgen, S.K., Chiarello, L. and Milbourne, S.A. (2007) Updated Competencies for Physical Therapists Working in Schools. Pediatric Physical Therapy, 19, 266-274. http://dx.doi.org/10.1097/PEP.0b013e318158ce90

[32] Feder, K.P. and Majnemer, A. (2007) Handwriting Development, Competency, and Intervention. Developmental Medicine \& Child Neurology, 49, 312-331. http://dx.doi.org/10.1111/j.1469-8749.2007.00312.x

[33] Hamstra-Bletz, L. and Blöte, A.W. (1993) A Longitudinal Study on Dysgraphic Handwriting in Primary School. Journal of Learning Disabilities, 26, 689-699. http://dx.doi.org/10.1177/002221949302601007

[34] Karlsdottir, R. and Stefansson, T. (2002) Problems in Developing Functional Handwriting. Perceptual and Motor Skills, 94, 623-662. http://dx.doi.org/10.2466/pms.2002.94.2.623

[35] Overvelde, A. and Hulstijn, W. (2011) Handwriting Development in Grade 2 and Grade 3 Primary School Children with Normal, at Risk, or Dysgraphic Characteristics. Research in Developmental Disabilities, 32, 540-548. http://dx.doi.org/10.1016/j.ridd.2010.12.027

[36] Smits-Engelsman, B.C., Niemeijer, A.S. and Van Galen, G.P. (2001) Fine Motor Deficiencies in Children Diagnosed as DCD Based on Poor Grapho-Motor Ability. Human Movement Science, 20,161-182. http://dx.doi.org/10.1016/S0167-9457(01)00033-1

[37] Smits-Engelsman, B.C.M., Van Galen, G.P. and Michels, C.G.J. (1995) Teachers Assessment of the Motor Proficiency Level and Motor Writing Skills of Elementary School Pupils. In: Smits-Engelsman, B.C.M., Theory Based Diagnosis of Fine-Motor Coordination Development and Deficiencies Using Handwriting Tasks, Ph.D. Thesis, Institute for Cognition and Information, Nijmegen, 33-49.

[38] Meulenbroek, R.G.J., Thomassen, A.J.W.M., Van Lieshout, H.P.M. and Swinnen, S.P. (1998) The Stability of PenJoint and Interjoint Coordination in Loop Writing. Acta Psychologica, 100, 55-70. 
http://dx.doi.org/10.1016/S0001-6918(98)00025-0

[39] Bosga-Stork, I.M., Bosga, J. and Meulenbroek, R.G.J. (2011) Intentional Control and Biomechanical Exploitation in Preparatory Handwriting. Human Movement Science, 30, 687-697. http://dx.doi.org/10.1016/j.humov.2010.06.007

[40] Visser, J., Van Laarhoven, A. and Ter Beek, A. (1996) AVi-toetspakket $-3^{\mathrm{e}}$ herziene versie [AVI Testpackage, Third Revision]. KPC, Den Bosch.

[41] Hamstra-Bletz, L., De Bie, J. and Den Brinker, B.P.L.M. (1987) Beknopte beoordelingsmethode voor kinderhandschriften: Experimentele versie [Concise Evaluation-Scale for Children's Handwriting: Experimental Version]. Swetz \& Zeitlinger, Lisse.

[42] Smits-Engelsman, B.C.M., Van Bommel-Rutgers, I. and Van Waelvelde, H. (2014) Systematische Opsporing Schrijfproblemen, SOS-2-NL.

[43] Van Waelvelde, H., De Mey, B. and Smits-Engelsman, B. (2008) Handleiding SOS; Systematische opsporing van schrijfmotorische problemen. Uitgeverij Revalidatiewetenschappen en Kinesitherapie Gent.

[44] Van Waelvelde, H., Hellinckx, T., Peersman, W. and Smits-Engelsman, B.C.M. (2012) SOS: A Screening Instrument to Identify Children with Handwriting Impairments. Physical \& Occupational Therapy in Pediatrics, 32, 306-319. http://dx.doi.org/10.3109/01942638.2012.678971

[45] Kandel, S. and Perret, C. (2015) How Does the Interaction between Spelling and Motor Processes Build up during Writing Acquisition? Cognition, 136, 325-336.

[46] Mammarella, I.C. and Cornoldi, C. (2005) Difficulties in the Control of Irrelevant Visuospatial Information in Children with Visuospatial Learning Disabilities. Acta Psychologica, 118, 211-228. http://dx.doi.org/10.1016/j.actpsy.2004.08.004

[47] Vidal, F., Meckler, C. and Hasbroucq, T. (2015) Basics for Sensorimotor Information Processing: Some Implications for Learning. Frontiers in Psychology, 6, 1-14. http://dx.doi.org/10.3389/fpsyg.2015.00033

[48] Peverly, S.T. (2006) The Importance of Handwriting Speed in Adult Writing. Developmental Neuropsychology, 29, 197-216. http://dx.doi.org/10.1207/s15326942dn2901 10 